tions are quite different. The animals usually kept have almost always a high value, and owing to the sub-division of property any losses sustained by small owners fall very heavily on them. In these circumstances, the main thing is to have an operation free from danger. Vaccination is abandoned for a long time after it produces an accident.

The method of vaccination which we have described above permits one to vaccinate cattle with certainty and safety against blackquarter. We believe it would be useless to recount here the advantages which it possesses over the methods hitherto employed.

To sum up:-

A single inoculation with a more or less attenuated pure vaccine, although realisable experimentally, is in practice attended with the risk of serious accidents.

Vaccination by means of two operations with pure vaccines, even when these are very attenuated, is not absolutely safe.

Vaccination with a mixture of immunising serum and virus is attended with the risk of immediate accidents, and it does not immunise with certainty.

The method which ought to be preferred consists in successively inoculating with immunising serum and a pure attenuated virus.

\title{
EPIZOOTIC ABORTION IN COWS AND ITS PREVENTION *
}

\section{By J. Penberthy, F.R.C.V.S., Royal Veterinary College, London.}

TECHNICALLY speaking, it is customary to make some distinction between miscarriage, abortion, and premature birth, but for all practical purposes it may be taken that "abortion," as it affects our subject, means expulsion of the fotus before its time and usually before it is capable of living after birth. It is an occurrence to which all mammals are liable, but experience tells us that among the domesticated animals it is much more frequent and serious as affecting cows and heifers. Conditions connected with the occurrence are so varied that abortions have come to be classified under two heads, "Sporadic" or "Accidental," and "Enzoötic," "Epizoötic," "Plague-like," or "Contagious."

Pregnant females of all species may, in isolated instances, cast their young as the result of some accident, such as a mechanical injury, some mental impression, etc. Sometimes such a cause affects but a single animal, while at other times it may affect a considerable number, e.g., narrow doorways, tympanites, fright, some poisons or infectious diseases, as Cattle Plague, Foot-and-Mouth Disease, or Pleuro-pneumonia. There is often an appreciable connection of cause and effect, and evidence that one abortion is not dependent on another abortion, though many be induced by a common cause. Such abortions cease when the evident cause ceases to exist. They are all placed in the category "Sporadic " or "Accidental." Under the head "Epizoötic," "Enzoötic," "Plague-like," "Contagious" are classed those abortions which usually affect many animals in a herd, flock, or stud, whose existence usually appears to be more 
or less dependent on some former case, and until recently the relation of cause and effect has been obscure. The terms "Picking," "Slinking," and "Slipping" or "Warping" are most commonly applied to the latter form.

This malady is recognised in the most ancient writings on the subject, and though it is very commonly believed that the epizoötic form is now more general and on the increase, there is ample evidence to show that in very early times its occurrence in flocks and herds was a matter of serious consideration. In Genesis xxxi., v. 38 , Jacob says to Laban, "All the twenty years that I have been with thee neither the ewes nor the she goats have cast their young." Mascall, our oldest English writer on stock, in his book on Cattle, published in I 567 , gives directions "how to keep cows which are great bellied in calf."

For the two subsequent centuries the records of cattle disease are very scant, but Lawrence, writing in 1805 , says "Cows are well known to be much given to abortion, slinking or slipping their calves in an early period of gestation; it is sometimes epidemic, and thence some people have supposed it to be contagious."

Three years later, Skellett, referring to abortion, remarks "it is an accident to which cows are very liable, it has often been known to spread like an infectious disease and great losses have been suffered by cow-keepers from the same." In I 837 Jonati tells us that abortion spread through dairies and flocks, and mares were often affected; and a little later writes fully on the occurrence of enzoötic abortion in cows, ewes, and mares. In I 85 I a prize essay written for the Royal Agricultural Society by Barlow states "abortion of cows is of such extensive prevalence amongst large stocks of cattle as fairly to be considered an epizoötic disease." In I 860 we learn from Musgrove that "the district of Hereford abounds with abortions both in bovine and equine species." In 1869 and I 870 we have records of "serious epidemics amongst cows, mares, and ewes in Scotland."

Abortion among cows had in 1886 become so prevalent and serious that a question was asked in the House of Commons as to the desirability of bringing it under the Contagious Diseases (Animals) Act. In 1894 the Royal Agricultural Society appointed a Committee to enquire into circumstances connected with its common occurrence, and urged the Minister of Agriculture to take steps to check it.

It is to the so-called "Epizoötic Abortion" that our attention is directed. The loss and disappointment associated with this affection are often extreme, and difficulties encountered in attempting to arrest its progress have led in many instances to the abandonment of breeding. As was before remarked, there are no statistics on which we may rely as to the extent of its prevalence or to form an opinion as to whether it is more common to-day than heretofore. We, however, know that its effect is sometimes such that for one or two years not a single calf in a herd is carried to full time. It has been asserted that of the cows in some districts as many as 60 per cent. abort. It is, however, not often that over 50 per cent. of a herd abort. Undoubtedly some modern conditions favour its spread, but the facts which have been adduced from history will, it is to be hoped, be somewhat reassuring, for if a century since the disease had assumed such alarming proportions as indicated by the contemporary writers, 
when no special means have been adopted to check its extension, unless there were in operation some natural hindrance the breeding of cattle must have ceased long ago.

It is not, however, its existence, but its prevention, which most concerns us, and in order to be in the most favourable position to adopt and carry out preventive measures it is well to appreciate what is known as to its nature and cause. It is when the cause and effect are distinctly associated that we are able and disposed to energetically direct our efforts to the definite object of attacking the cause.

The contents of the womb may be expelled as a result of impressions on the nervous system through some of the ordinary or special senses, inducing the state of fright, etc., bringing about violent contractions of the womb or "heaving." Expulsion, however, usually results from some changes in those contents or of the relation between them and the womb. Under natural conditions, as soon as the foetus is capable of a separate existence it becomes independent-it is not a part of the being of its mother, but a foreign body and an irritant unfit to remain there and is cast off, in accordance with a principle exemplified in coughing, vomiting, sneezing, etc. Anything, therefore, which interteres with the vitality of the foetus, or breaks down the relations of the foetus to the womb, will bring about expulsion of the former.

Without regarding abortion in this light, the greatest variety of circumstances have been brought forward to account for its occurrence. Witchcraft, sympathy, smells, sights, frights, domestication, sewage, diet, climate, even evil spirits and a thousand other agencies, have been accredited with the power. The theory of contagion, however, had a century ago forced itself on many observers, the majority of whom were quite unwilling to accept it, and while advocating the application of disinfectant measures, took the trouble to state that it was not on the. ground that affection was due to contagion, but to sympathy. In more recent times, with improved methods of observation and increased scientific knowledge, the view of a contagious nature had become firmly held, and epizoötic abortion, like some other diseases, as tuberculosis, was generally recognised as contagious long before the causal germ was identified.

The publication (in 1896 ) of the results of experiments made by a celebrated Danish veterinary surgeon, Dr Bang, and his discovery of the germ, placed the matter on a more satisfactory basis. This observer discovered in the envelopes of the foetus and between them and the walls of the womb during life, before abortion took place, also in the abortion, afterbirth, and discharge from the genital passages of the animal which had aborted, certain bacilli or germs. By introducing these into the genital passages or into the veins of healthy pregnant cows abortion was induced. Though conclusive evidence has not yet been forthcoming, it is thought possible that the same effect may be induced by swallowing the germs with food or water, or even by their entrance into the air passages. It is, however, highly probable that under natural circumstances the germs enter by the vagina. There is every reason for supposing that a large proportion of cows to whose womb the germs gain access abort, but it is possible that in rare instances a cow's womb may be infected and contain the germs and 
yet abortion not follow, so that a cow which has not aborted may possibly be dangerous as a means of spreading the disease.

Epizoötic abortion of cows is therefore due to a disease of the womb and membranes of the foetus induced by germs, at any rate usually discharged by an infected cow. This reservation is made because though there is no room for doubting that in the great majority of cases the germ is derived from an affected cow, we are not yet in a position to say positively that such germs may not be derived from other sources, though, it must be said that our experience does not support such a view. It cannot, however, be too emphatically stated that the infected cow is the paramount danger, and that our attempts to prevent must be based on an appreciation of this fact. She remains a source of mischief as long as she discharges or harbours the virus. There is also good reason for believing that the germs retain their power of inducing the diseases some time after they are discharged.

It is only by preventing access of these germs to healthy animals that we may hope to prevent occurrence of the disease.

Anything contaminated with discharge from an infected cow may prove a medium for the conveyance of the disease to the healthy cow. It will then be easily understood how the floor, etc., of a byre, or a spot of pasture where abortion has taken place, or where an infected animal stands, attendants, certain parts of the cow, especially the tail, or a bull having served an infected cow, etc., may be a source of danger.

It is not yet proved whether non-pregnant animals may contract the disease in their wombs and so become, though unsuspected, means of propagating the malady; but, as there is apparent no specific reason why they should not, a certain amount of suspicion must rest on even non-pregnant animals which have been exposed to the chances of infection.

The period which elapses between the access of the germ to the healthy animal and the occurence of abortion is a matter for further inquiry. From the reports of experiments already carried out, this period would appear to vary from twenty-one days to ten weeks, i.e., when the material has been introduced into the genital passage. It must not, however, be concluded from the result of experiments, in which the infecting matter has been directly and purposely inserted into the genital passages, that the germs will always be acquired so readily when healthy animals are merely brought into contact with the affected, that is to say, by simple cohabitation.

It is equally important to bear in mind that a short period of cohabitation with aborting cows may be sufficient to infect those previously healthy. Naturally this period must vary widely, so that after the introduction of an infected animal into a healthy herd it is not possible to know when other cows will abort. It has been known to occur six weeks after such introduction.

Even from experimental cases it has been observed that the effect of introducing the germs into pregnant cows is not always the same; indeed, in some instances there is no appreciable effect, and the calf is carried to full time. Under natural conditions we observe the same variation after exposure to the chances of infection, and it must be remarked, as one of the most noticeable and important characteristics 
of the malady, that in the course of an outbreak a certain degree of immunity is acquired. It would seem to be similar to the course observed in small-pox and some other well known contagious diseases, in which one attack confers some protection. Indeed, it is one of the most satisfactory points to note in connection with this scourge that there is a natural tendency for it to exhaust itself and die out in the course of from three to five years. This natural beneficial course is, however, interfered with if any fresh animals are introduced into the aborting herd. If such a practice is persisted in the outbreak may continue indefinitely. The explanation of this circumstance is not clear. We do not know how long acquired immunity lasts; it may be that cows again become susceptible, or perhaps the germs acquire fresh power by passing through freshly introduced cows.

The effect of the disease on the system of the cow is often trifling; indeed, it frequently happens that the first evidence of a cow's having aborted is the on-coming of cestrum, which usually occurs from three to eight days after. This, of course, is usually in the earlier cases in an outbreak, and unfortunately it permits of contamination of the herd before the existence of the disease is suspected.

When it is recognised that the disease is established in a herd, and a sharp look out is kept, occasionally some time before the expulsion of the womb contents there may be noticed some change in the quantity and quality of the milk, or a brownish discharge from the genital organs. Rarely is there any marked constitutional disturbance to indicate its approach.

The measures which have been at different times adopted to prevent or arrest the affection have been on a par with the suggested causes. Among the more common it may be of interest to recall the horse shoe, the killed fox, or magpie nailed to the cow-house door; the goat kept in the byre, and the burial of an abortion at its threshold. Abortions were believed to be due to some inscrutable mystic agencies, and equally unintelligible measures were resorted to to counteract their influence.

Preventive measures must, however, be founded on the knowledge that the disease is contagious, and must. be carried out under the conviction that our herds can only be maintained free from the risks by preventing access of the germs-the essence of this contagious quality. When considering measures for preventing the introduction of the disease into healthy herds, the fact will be borne in mind that the cow or heifer which has aborted, or is already affected with the malady of which abortion is the result, but still pregnant, and the bull which has served aborted cows, must be a ready means by which the germs may be transmitted from one situation to another, and that it is not yet proved that healthy animals which have been associated with the affected may not carry the contagion.

The matter is often surrounded with insurmountable obstacles, and inasmuch as there are no means of identifying dangerous animals it is impossible to avoid all the risks of contaminating a herd except by not introducing fresh animals or by purchasing only from herds free from abortion. Under present conditions this is rarely practicable, for dairies and breeding herds must be replenished, and to trace the origin of animals bought in open market before purchase is not often possible. It is to be feared that it is commonly regarded the easiest 
way out of the trouble to sell cows which have aborted, and this is, I believe, a common practice. It is hard to conceive of any means by which greater injury can be done to a breeder than by the introduction of the germ of this affection.

There is now no question as to epizoötic abortion being contagious and capable of being conveyed by animals from aborting herds. The losses to stock-breeders and the country at large are serious and apparently on the increase. The time has arrived when it should be legally regarded as a criminal offence to sell an animal from an aborting stock without stating the fact to the intending buyer. I think the Minister of Agriculture would be justified in using means for bringing the affection within the operation of the Contagious Diseases (Animals) Act. This would supply a partial if not complete safeguard against the introduction of the malady into healthy situations, an event now not under the control of the breeder. Isolation of new animals is not often practicable, and no cow from an aborting stock may be said to be safe. It is, however, advisable that newly purchased animals should be kept as far as possible from the chance of affecting pregnant cows. Thus, they may be placed in the lower portion of a byre, so that should abortion take place or contaminated matter be discharged from the genital passages they would be less likely to reach the healthy. Barren cows should always be suspected.

Next to keeping the malady out of a herd comes the consideration of eradicating it, or arresting its progress, when established, and this can only be effected by preventing its spread from the affected to the healthy, for to attempt to avert the expulsion of the foetus after the womb is infected is useless, if not impossible. The difficulties encountered in such an attempt are by no means light. We have no means of ascertaining when a cow is infected and so to a greater or lesser degree dangerous, so that it must sometimes happen that before any animal is at all suspected she has spread the disease to her fellows. Inasmuch as it cannot be determined except by bacteriological examination if any abortion be due to contagion or other cause, it is well to treat all as though contagious.

It is at the period of abortion and that immediately following it that the aborting animal is most dangerous. The abortion, afterbirth, and discharges from the genital passages swarm with the germs. The cow should be isolated on manifestation of the earliest symptoms of approaching abortion, or of having aborted. The foetus and its membranes should be destroyed by fire or chemicals, or buried out of reach of cattle. The place in which abortion occurred should be thoroughly disinfected ; and, while it cannot be doubted that the more thorough the disinfection the greater are the chances of success, the gutter, the floor, etc., under and behind the cow, should receive special attention.

As carbolic acid and some other disinfectants have strong odours and are liable to taint the milk, it is advisable to use a solution of sulphate of copper for this purpose. All cows in the shed should have their external genitals, tails, and back parts generally, sprayed daily with a disinfectant, such as solution of lysol or chloride of zinc, with a view of destroying any germs possibly resting there. Powdered lime freely used on the floor is believed to be very useful. Manure from byres where abortion has taken place should not be used for pastures 
on which cows will graze. Should abortion take place on the pas ture it should be similarly dealt with, the cow being brought into the house and kept isolated. All cows which have aborted should have the vagina syringed out daily with some disinfectant solution as I per thousand mercuric chloride or 2 per cent. of carbolic acid. It is also advocated that the womb itself, the source of the germs, should be washed out three times a week for three weeks after aborting, but this should not be undertaken except under direction of a veterinary surgeon, as alarming straining sometimes follows the injection, though no serious results have come to our knowledge.

It must not be forgotten that attendants may convey the contagium, and that isolation implies the attendance of some one who does not come in contact with non-aborting animals.

Bulls known to have served cows which have aborted should not be used for others. Their parts should be syringed and sponged with some non-irritating disinfectant daily, or at least after each service, and it will not be safe to use the animal for service of healthy cows for some weeks.

The next consideration is, what to do with cows which have aborted. They usually come into œstrun a few days after aborting, and, if then served, almost invariably abort again. Service should not be attempted for at least three months, during which time disinfection should be carried out. Once having aborted, there is usually a tendency to do so again if service occurs soon after, but this tendency diminishes as time goes on, and a certain degree of immunity follows or the germs become less virulent. The method of dealing with such cows will largely depend on the numbers to be dealt with. If only a small number, fattening for the butcher, while being strictly separated from the healthy, is probably the most radical and economical measure.

New purchases should be most carefully kept from chances of contamination, for though there appears a natural tendency for the disease to die out after from two to five years, the introduction of fresh animals appears in some way to maintain its existence.

The adoption of the foregoing measures in their entirety involves an immense amount of trouble and annoyance. In some instances it may not be possible; while success will largely depend on the thoroughness with which they are carried out, it is advisable to apply treatment on the same lines as far as circumstances may permit.

\title{
ACCIDENTS CAUSED BY "SURFACE-CONTACT" ELECTRICAL TRAMWAYS. ${ }^{1}$
}

\author{
By P. J. CAdiot, Veterinary College, Alfort, Paris.
}

THE first "surface-contact" electrical tramways laid down in Paris and its environs passed through streets in which electrical energy was distributed by two systems, known by the names of their inventors: the system Diatto and the system Claret-Vuillemier. The latter has not become popular. At the present time almost all the surfacecontact lines are equipped with the Diatto system.

1 Translated from the "Recueil de Méd. Vét.," 15th May 1902. 